Quantification and characteristics of household inflation expectations in Switzerland

Rina Rosenblatt-Wisch and Rolf Scheufele

SNB Working Papers

$11 / 2014$ 


\section{Legal Issues}

\section{DISCLAIMER}

The views expressed in this paper are those of the author(s) and do not necessarily represent those of the Swiss National Bank. Working Papers describe research in progress. Their aim is to elicit comments and to further debate.

\section{COPYRIGHTC}

The Swiss National Bank (SNB) respects all third-party rights, in particular rights relating to works protected by copyright (information or data, wordings and depictions, to the extent that these are of an individual character).

SNB publications containing a reference to a copyright (C) Swiss National Bank/SNB, Zurich/year, or similar) may, under copyright law, only be used (reproduced, used via the internet, etc.) for non-commercial purposes and provided that the source is mentioned. Their use for commercial purposes is only permitted with the prior express consent of the SNB.

General information and data published without reference to a copyright may be used without mentioning the source. To the extent that the information and data clearly derive from outside sources, the users of such information and data are obliged to respect any existing copyrights and to obtain the right of use from the relevant outside source themselves.

\section{LIMITATION OF LIABILITY}

The SNB accepts no responsibility for any information it provides. Under no circumstances will it accept any liability for losses or damage which may result from the use of such information. This limitation of liability applies, in particular, to the topicality, accuracy, validity and availability of the information.

ISSN 1660-7716 (printed version)

ISSN 1660-7724 (online version)

(C) 2014 by Swiss National Bank, Börsenstrasse 15,

P.O. Box, $\mathrm{CH}-8022$ Zurich 


\title{
Quantification and characteristics of household inflation expectations in Switzerland ${ }^{a}$
}

\author{
Rina Rosenblatt-Wisch ${ }^{\mathrm{b}} \quad$ Rolf Scheufele ${ }^{\mathrm{c}}$
}

30 October, 2014

\begin{abstract}
Inflation expectations are a key variable in conducting monetary policy. However, these expectations are generally unobservable and only certain proxy variables exist, such as surveys on inflation expectations. This paper offers guidance on the appropriate quantification of household inflation expectations in the Swiss Consumer Survey, where answers are qualitative in nature. We apply and evaluate different variants of the probability approach and the regression approach; we demonstrate that models which include answers on perceived inflation and allow for time-varying response thresholds yield the best results; and we show why the originally proposed approach of Fluri and Spörndli (1987) has resulted in heavily biased inflation expectations since the mid-1990s. Furthermore, we discuss some of the key features of Swiss household inflation expectations, i.e. the fact that there has been a shift in expectation formation since 2000 (expectations are better anchored and less adaptive, and there is lower disagreement of expectations). We suggest that this may be linked to the Swiss National Bank's adjustment of its monetary policy framework around this time. In addition, we outline how expectation formation in Switzerland is in line with the sticky information model, where information disseminates slowly from professional forecasters to households.
\end{abstract}

JEL-Classification: C22, C82, E31, E50

Keywords: Inflation expectations, quantification of qualitative surveys, credibility, expectation formation, sticky information

${ }^{a}$ We thank an anonymous referee of the SNB Working Paper Series and participants of the Swiss National Bank Brown Bag Seminar, the MMF annual conference and the CIRET conference for helpful comments. The views expressed in this paper are our own and do not necessarily represent the views of the Swiss National Bank.

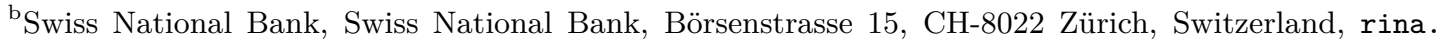
rosenblatt@snb.ch

${ }^{\mathrm{c}}$ Swiss National Bank, Swiss National Bank, Börsenstrasse 15, CH-8022 Zürich, Switzerland, rolf. scheufele@snb.ch 


\section{Introduction}

Inflation expectations play a crucial role in modern macroeconomics and are a key variable for conducting monetary policy. However, expectations are generally unobservable and only certain proxy variables exist. One way to retrieve information on expectations is to employ survey measures of expected inflation. For Switzerland, surveys on inflation expectations are rare and long time series data hardly exist. The only major source of direct expectation measures is provided in the form of qualitative household responses on inflation expectations in the Swiss Consumer Survey. However, despite the long collection period (since 1972q4 on a quarterly basis), this survey has been mainly ignored by the empirical literature so far. ${ }^{1}$

In this paper we analyze several methods to appropriately quantify the household inflation expectations in the Swiss Consumer Survey. First, we show why the originally proposed approach of Fluri and Spörndli (1987) has resulted in heavily biased inflation expectations since the mid-1990s. Second, we apply and evaluate different variants of the probability approach (Theil, 1952; Carlson and Parkin, 1975; Dasgupta and Lahiri, 1992; Smith and McAller, 1995) and the regression approach (Pesaran, 1987). In particular, we argue that the link between observed and perceived inflation rates changed substantially over time (namely in terms of the response thresholds) with consequences for the quantified inflation expectations.

Generally, we make use of the relationship between survey responses on perceived past price developments and observed inflation rates to scale the measure on expected inflation (as suggested by Berk, 1999; Nielsen, 2003). The unique feature of our data set (compared to e.g. the surveys of the European Commission) is the fact that there is a one to one mapping between the answers of perceived and expected inflation (the survey comprises the same kind of questions and the same categories of answers).

Our analysis indicates that three quantification methods that allow for some time variation in the response thresholds perform equally well: Kalman filter based estimates, rolling regression techniques and smooth transition estimates. The latter method explicitly links the quantification thresholds to past inflation trends and is new in this setting. All three

\footnotetext{
${ }^{1}$ The only exception we are aware of is Fluri and Spörndli (1987).
} 
variants have the advantage that they do not require the assumption of unbiasedness of inflation expectations. As a byproduct we are able to compute a measure of disagreement of inflation perceptions and expectations which follows naturally from the quantification methods.

The quantified series show that there has been a significant shift in expectation formation after 2000. Inflation expectations have become better anchored, but less adaptive and forward-looking. Additionally, expectations display lower disagreement after 1999. The shift coincides with the adjustment to a new policy framework with an explicit definition of price stability by the Swiss National Bank (SNB).

Finally, we compare the quantified inflation expectations of households with those of professional forecasters (data from Consensus Economics). In terms of predictability of inflation the quantified household expectations perform similar to those of professionals. However, causality tests suggest that professional forecasts Granger cause household expectations and not vice versa. We show that a sticky information model as proposed by Carroll (2003) is able to explain the link between household and professional forecasters' inflation expectations. Our results suggest that about $25 \%$ of households update their information set in each quarter, which closely matches the results for the US.

\section{Data set}

The Swiss Consumer Survey is conducted quarterly by the State Secretariat for Economic Affairs (SECO). Question 2 of the Consumer Confidence Survey comprises an assessment of past price fluctuations and expected price developments:

- 2.1 How, in your view, have prices changed over the last 12 months?

Have they ...risen sharply; risen slightly; remained virtually unchanged; fallen slightly; fallen sharply; Don't know; No answer given.

- 2.2 How, in your view, will prices change over the next 12 months?

Will they ...rise sharply; rise slightly; remain virtually unchanged; fall slightly; fall sharply; Don't know; No answer given. 
The survey was conducted for the first time in 1972q4. From 1972q4 until 1996q4 negative price changes were summarized in one category. As negative price changes were summarized between 1972 and 1996 we will do the same for the remaining data.

In the beginning the sample size was around 500 households, from 1981q1 until 2012q1 the survey was based on answers of roughly 1100 households and from then on answers of approximately 1200 households.

An advantage of the Swiss survey is that both questions regarding the near past and the near future are phrased in the same way. Other surveys often change their pattern of asking, e.g. the European Commission Consumer Survey (EC) asks in retrospect about changes in the price level, whereas the forward-looking question focuses on changes in the inflation rate.

Figure 1 gives an overview of the evolution of the different answer categories for both, inflation perceptions and inflation expectations. Over time the shares of the different answer categories are not stable, but move quite distinctly as the perception about past price developments and expectations about future price developments change.

\section{The quantification of qualitative data}

There has been a long tradition to transform aggregate qualitative response data into quantitative measures of expectations (see Theil, 1952, for a first application). The basic idea is that fractions of aggregated responses reveal something about the magnitude of expected price changes. Generally, we can distinguish two basic approaches to quantify aggregate responses on qualitative expectations: a) the probability method and b) the regression approach. The probability method assumes that the answers of the respondents follow from a subjective probability function that can be characterised by a few parameters. The regression approach is less causal and simply utilizes the statistical relationship of respondents' perceptions of the past (by means of a time series regression) as a yard stick for the quantification of respondents' expectations about the future (see Pesaran, 1987). 
Figure 1: Shares of answers

Inflation perceptions
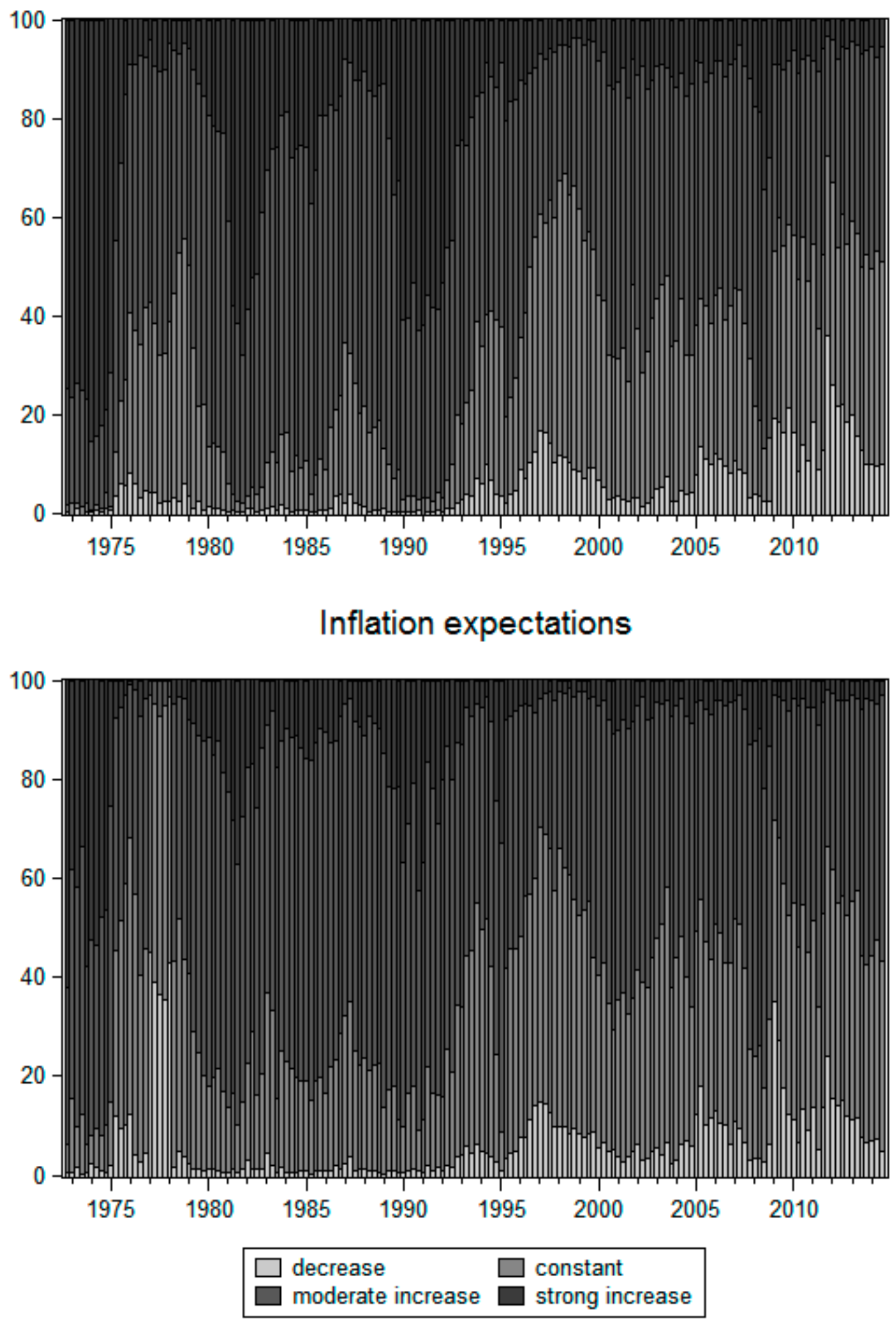


\subsection{Expert versus household expectations}

Before we present the method for quantification some general considerations should be taken into account. First, to judge the quality of our quantification method, it would be desirable to compare it with quantitative inflation expectations. For households in Switzerland however, these measures do not exist. Where possible, we compare the quantified expectations with forecasts made by professionals (i.e. with Consensus Economics from 1998 onwards). As another benchmark, we investigate how closely our quantified expectation measures follow the realized inflation rate and therefore different error measures are calculated. Throughout our analysis we never try to minimize specific error measures (instead we try to model the relationship of observed and perceived inflation rates and use this relationship to calculate the expectation series).

Another issue is the reliability of inflation expectation measures obtained from household surveys. A priori it is unclear whether mostly uninformed households have any intuition about aggregate price changes and inflation developments. However, for the US, the results based on the Michigan survey are quite encouraging. For instance, Mankiw et al. (2004) document smaller forecast errors (in terms of MSEs) of quantitative inflation expectations of households which are on average more accurate than those of professionals (for a comparative sample). Even the quantified information from the qualitative answers perform only marginally worse. On the contrary, Carroll (2003) documents that survey measures from the Michigan survey are substantially larger compared to those of the Survey of Professional Forecasters (SPF). Ang et al. (2007) find that survey based measures do beat standard time-series models of inflation. Surveys obtained from professionals are slightly superior relative to household surveys. Generally, it remains open whether survey expectations from professionals are indeed more accurate than those of households.

\subsection{The probability approach}

The proposed probability method for the Swiss household survey relies on the procedure popularized by Carlson and Parkin (1975), which is often called Carlson-Parkin method (CP method). The basic method was proposed for three categorial answers where the respondents can choose between the answers 'prices will increase', 'prices will decrease' 
and 'prices will remain constant'. This method has been used quite extensively (see Nardo, 2003, for an overview) and can be easily modified for more than three categorial answers. ${ }^{2}$ Fluri and Spörndli (1987) also employ the standard Carlson-Parkin method for calculating inflation expectations from the Swiss household survey.

In the following, we propose some refinements to the basic probability approach to extract more reliable information from the data on price expectations. In particular we employ the answer on inflation perceptions to rescale the data on price expectations (see Pesaran, 1987; Batchelor and Orr, 1988; Berk, 1999, for a similar proposal). This procedure has the advantage that one does not need to impose unbiasedness of inflation expectations. Instead, we can use the observed relationship between effective past price movements and survey answers on perceived inflation.

More formally, the probability method assumes that each respondent $i$ forms a subjective probability distribution for future inflation which can be characterized by a mean $\mu_{i t}$ and a standard deviation $\sigma_{i t}$ and answers the question according to this distribution. This distribution $f_{i}\left(y_{i t}\right)$ is assumed to be the same across agents. In the consumer survey the respondents can choose among four categories of answers. The method assumes: The respondents answer prices will 'go down', 'stay the same', 'will rise moderately' and 'will rise strongly' if $y_{i t} \leq-\delta_{i t}^{L},-\delta_{i t}^{L}<y_{i t} \leq \delta_{i t}^{U}, \delta_{i t}^{U}<y_{i t} \leq \lambda_{i t}$ and $y_{i t}>\lambda_{i t}$. The range between $-\delta_{i t}^{L}$ and $\delta_{i t}^{U}$ can be interpreted as a 'just-noticeable difference' in inflation and the threshold $\lambda_{i t}$ separates the 'moderate rise' category from the 'strong rise' category.

Given the response fractions from the surveys one can define the probabilities that characterise the aggregate distribution function. Figure 2 gives a graphical representation. The aggregate probabilities can be calculated from the survey responses according to $P\left(y \leq-\delta_{i t}^{L}\right)=A_{t}, P\left(y \leq \delta_{i t}^{U}\right)-P\left(y>-\delta_{i t}^{L}\right)=B_{t}$ and $P\left(y \leq \lambda_{i t}\right)-P\left(y>\delta_{i t}^{U}\right)=C_{t}$. We denote $a_{t}, b_{t}$ and $c_{t}$ as the abscissae of the distribution function corresponding to the cumulative probabilities $A_{t}, A_{t}+B_{t}$ and $A_{t}+B_{t}+C_{t}$, respectively. Therefore, we need to specify a specific distribution function. For convenience a normal distribution is employed. ${ }^{3}$ The same method can not only be used for quantifying inflation expectations, but

\footnotetext{
${ }^{2}$ Batchelor and Orr (1988), Berk (1999) and Nielsen (2003), among others, employed to probability approach in the tetratomous and pentachotomous case.

${ }^{3}$ Generally, one would choose among other distributions (e.g. logistic or a scaled t-distribution). However, the concrete choice of the distribution has only a marginal impact on the results (which is in line with Dasgupta and Lahiri, 1992; Scheufele, 2011).
} 
Figure 2: Joint probability distribution function

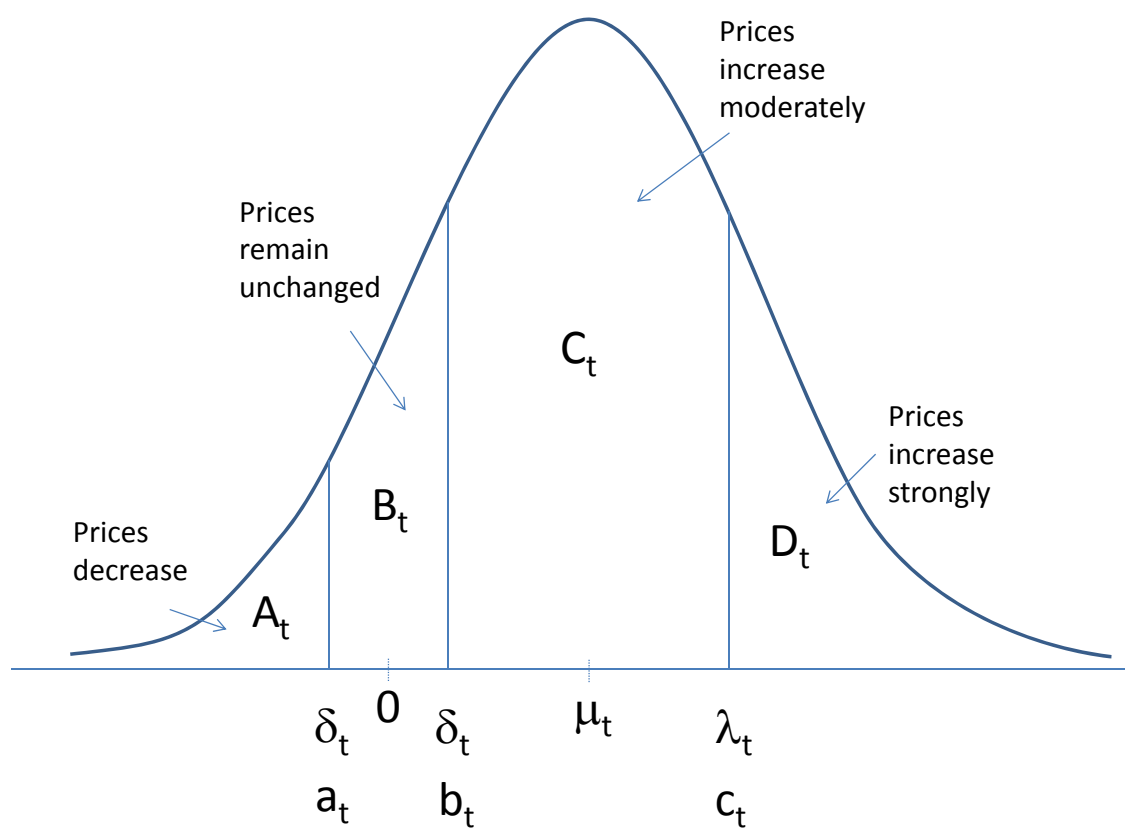

also for the perceived price changes of the past. Figure 2 gives a graphical representation.

The probability method assumes that individual subjective probability distributions can be aggregated to a joint probability distribution which is characterized by a mean $\mu_{t}$ and a standard deviation $\sigma_{t}$ for the expected inflation rate. If we further assume that the indifference interval is symmetric $-\delta_{t}^{L}=\delta_{t}^{U}=\delta_{t}$ around zero, we can express the first two moments as functions of the quantiles of a normal distribution $a_{t}, b_{t}$ and $c_{t}$ and the rate of inflation which is seen as moderate $\lambda_{t}$. In this case, the mean expected inflation rate $\mu_{t}=E_{t} \pi_{t+4}$ is given by

$$
\begin{gathered}
\mu_{t}=\lambda_{t}\left(a_{t}+b_{t}\right) /\left(a_{t}+b_{t}-2 c_{t}\right), \quad \sigma_{t}=-2 \lambda_{t} /\left(a_{t}+b_{t}-2 c_{t}\right) \text { and } \\
\delta_{t}=\lambda_{t}\left(a_{t}-b_{t}\right) /\left(a_{t}+b_{t}-2 c_{t}\right) .
\end{gathered}
$$

The particular choice of the scaling parameter (which is given by $\lambda_{t}$ in our case) turns out to be the crucial assumption for converting qualitative response data. Carlson and Parkin (1975) and Fluri and Spörndli (1987) assume that the scaling parameter is time 
invariant. They scale inflation expectations to match the average inflation rate over the sample period:

$$
\lambda_{t}=\lambda=\frac{\sum_{t=1}^{T-4} \pi_{t+4}}{\sum_{t=1}^{T-4}\left(a_{t}+b_{t}\right) /\left(a_{t}+b_{t}-2 c_{t}\right)},
$$

where $\pi_{t+4}$ is the realized one year ahead inflation rate. Note that this assumption automatically implies that inflation expectations are on average unbiased. ${ }^{4}$ We circumvent this rather strong assumption by calculating $\lambda_{t}$ using the information based on past inflation perceptions. Additionally, the assumption of a time-invariant scaling parameter is rather strong. For instance, Batchelor and Orr (1988) argue that the indifference interval may depend on the level of past inflation rates or the standard deviation of inflation and should therefore be time varying. Therefore, we discuss methods that allow for time variation of the scaling parameter.

To calibrate $\lambda_{t}$ we utilize consumers assessment on past price developments (similar to Berk, 1999). Since past price developments can be observed and should be related to an aggregate price index, we can rescale the fraction of survey answers to match on average the realized inflation rate. Similar to the answers on expected price developments, we denote $a_{t}^{\prime}, b_{t}^{\prime}$ and $c_{t}^{\prime}$ as the abscissae of the distribution function for perceived inflation. Then perceived inflation can be expressed as $\mu_{t}^{\prime}=\lambda_{t}\left(a_{t}^{\prime}+b_{t}^{\prime}\right) /\left(a_{t}^{\prime}+b_{t}^{\prime}-2 c_{t}^{\prime}\right)$. This approach assumes that the response threshold is the same for inflation perceptions and expectations. ${ }^{5}$

\subsection{Allowing for time-varying scaling parameter}

\section{Change in the inflation environment}

The main idea of allowing for a time-varying scaling parameter is to better capture shifts in the inflation environment. Figlewski and Wachtel (1981) based on the Livingston survey strongly argue that it is essential to allow for time variation in the expectation formation process. Breitung and Schmeling (2013) find evidence that allowing for time variation of

\footnotetext{
${ }^{4}$ Alternatively, Batchelor (1982) put forward another form of unbiasedness: the notion of statistical unbiasedness. In this case, $\hat{\lambda}$ is obtained from the regression of $\pi_{t+4}$ on $\left(a_{t}+b_{t}\right) /\left(a_{t}+b_{t}-2 c_{t}\right)$. For the Swiss Consumer Survey, both methods produce similar results for $\lambda$.

${ }^{5}$ One extreme is to assume that the perceived inflation rate always equals the realized inflation rate, which implies that $\pi_{t}^{P}=\mu_{t}^{\prime}=\pi_{t}$. In this case, the parameter $\lambda_{t}$ is perfectly determined and time varying (this has been applied by Nielsen, 2003). However, we state that only on average this assumption holds, which implies $\pi_{t}^{P}=\mu_{t}^{\prime}=\pi_{t}+u_{t}$, with $u_{t}$ of mean zero and finite variance.
} 
the response thresholds is the main issue to improve the basic CP method.

In the context of the probability approach this means the following: What respondents assess or feel to be a moderate rise in prices could change over time. If people live in an environment of generally higher inflation rates and higher variance in the inflation rates, their threshold of what they feel to be a moderate price increase might be higher. In times of low inflation rates and low volatility people get used to a different environment and their assessment of what they believe to be a moderate price increase is most probably lower. Lahiri and Zhao (2014) find for US data that there is a statistically positive link between the actual inflation rate and the thresholds, and inflation uncertainty has an influence on the width of the indifference interval.

In Switzerland, the inflation environment changed in the first half of the nineties (see Stulz, 2007). The mean and the variance of inflation have both decreased in the nineties compared to previous years - there was a shift towards lower and more stable inflation. ${ }^{6}$ To allow therefore for time variation might improve our quantification results.

\section{Rolling regressions}

A simple way of introducing time variation of the parameter $\lambda_{t}$ is by performing regressions based on a rolling window. Lahiri and Zhao (2014) applied this simple version of timevarying parameters. In our case we run the regression $\pi_{t}=\lambda\left(a_{t}^{\prime}+b_{t}^{\prime}\right) /\left(a_{t}^{\prime}+b_{t}^{\prime}-2 c_{t}^{\prime}\right)+u_{t}$ using a sample window from $t-w+1$ to $t$. This implies

$$
\hat{\lambda}_{t}^{r}=\frac{\sum_{k=t-w+1}^{t}\left(a_{k}^{\prime}+b_{k}^{\prime}\right) /\left(a_{k}^{\prime}+b_{k}^{\prime}-2 c_{k}^{\prime}\right) \pi_{k}}{\sum_{k=t-w+1}^{t}\left(\left(a_{k}^{\prime}+b_{k}^{\prime}\right) /\left(a_{k}^{\prime}+b_{k}^{\prime}-2 c_{k}^{\prime}\right)\right)^{2}} .
$$

This procedure has the advantage that no future information is included in estimating $\lambda$. However, this method does not allow for rapid changes since all observations in the window sample are treated equally. Furthermore, one needs to calibrate the parameter $w$ of the window size and the first $w$ observations of the survey cannot be used. However, Lahiri and Zhao (2014) report encouraging results for the Michigan survey by allowing for a rolling window.

\footnotetext{
${ }^{6}$ Stulz (2007) finds a structural break point for September 1993.
} 


\section{Time-varying coefficients model}

Another way of introducing time variation is to assume that coefficients might change permanently in time. Seitz (1988) proposed a state space model and used the Kalman filter to estimate a time-varying response threshold for the case with three categorial answers. Under the assumptions made for eq. (1) the state space system consists of two equations, given by

$$
\begin{aligned}
& \pi_{t}=\lambda_{t}\left(a_{t}^{\prime}+b_{t}^{\prime}\right) /\left(a_{t}^{\prime}+b_{t}^{\prime}-2 c_{t}^{\prime}\right)+u_{t}, \\
& \lambda_{t}=\lambda_{t-1}+e_{t} .
\end{aligned}
$$

While the first equation is the measurement equation which relates the observed inflation rate to the qualitative answers on perceived inflation, the second equation specifies the law of motion of the unobserved state variable (or transition variable). In our case this is the rate of inflation which is qualified as a 'moderate' rise in prices. For applying the Kalman filter we assume that $u_{t} \sim N\left(0,(1-\gamma) \sigma^{2}\right)$ and $e_{t} \sim N\left(0, \gamma \sigma^{2}\right)$ and initial conditions for the state (and its variance). Next, we are able to estimate the unknown parameters $\sigma$ and $\gamma$. Finally, we can apply the Kalman filter and smoother to obtain the filtered or smoothed values of the unobserved state (which are given by $\hat{\lambda}_{t}^{f i l}$ and $\hat{\lambda}_{t}^{s m}$, respectively). ${ }^{7}$

The time-varying coefficients model allows to estimate $\lambda_{t}$ at each point in time (therefore this procedure avoids the problem of missing observations at the beginning of the sample). Moreover, the model is more flexible to take into account more rapid changes in the response threshold. Similar to the method of rolling windows, the time-varying coefficients model is a purely statistical model and it leaves open what causes the time variation in $\lambda$.

\section{Smooth transition models}

As an alternative we propose a smooth transition model (STM) to allow for time variation in the scaling parameter. The idea is to define a transition variable which moves the scaling

\footnotetext{
${ }^{7}$ Note, that smoothed implies that each estimated value is a function of the past, present and future, whereas the filtered series depend only on the past and present observations.
} 
parameter of the probability approach in time. This model allows for a flexible impact and can be thought of some sort of regime-switching model. The appeal of this model is that we can relate the transition of the scaling parameter to some economic variable. As pointed out by Batchelor and Orr (1988) we should expect the scaling parameter to be a function of the past inflation level (or trend inflation) and/or of the standard deviation of inflation. This model allows to test for these relations.

More precisely, our smooth transition model has the following form:

$$
\mu_{t}=\phi\left(a_{t}^{\prime}+b_{t}^{\prime}\right) /\left(a_{t}^{\prime}+b_{t}^{\prime}-2 c_{t}^{\prime}\right)+\phi^{\prime} G\left(s_{t} ; \gamma, c\right)\left(a_{t}^{\prime}+b_{t}^{\prime}\right) /\left(a_{t}^{\prime}+b_{t}^{\prime}-2 c_{t}^{\prime}\right)+\epsilon
$$

where $G\left(s_{t} ; \gamma, c\right)$ is the transition function which is a continuous function that is bounded between 0 to 1 . The transition variable $s_{t}$ is either a measure of trend inflation or of inflation volatility. As the transition function we choose a first order logistic function

$$
G\left(s_{t} ; \gamma, c\right)=\left(1+\exp \left\{-\gamma\left(s_{t}-c\right)\right\}\right)^{-1}, \gamma>0
$$

The resultant model is a logistic ST model (see e.g. van Dijk et al., 2002). The parameter $\gamma$ defines the smoothness of the transition from one regime to the other. ${ }^{8}$ The parameter $c$ can then be interpreted as the threshold between the two regimes. Given this model, the estimated scaling parameter $\hat{\lambda}_{t}^{s t}$ is time varying, given as $\hat{\lambda}_{t}^{s t}=\hat{\phi}+G\left(s_{t} ; \hat{\gamma}, \hat{c}\right) \hat{\phi}^{\prime}$. The clear advantage of the STM approach is that the response threshold is directly related to an observed variable.

Table 1: Estimation results for the smooth transition model

$$
\begin{gathered}
\pi_{t}=\phi\left(a_{t}^{\prime}+b_{t}^{\prime}\right) /\left(a_{t}^{\prime}+b_{t}^{\prime}-2 c_{t}^{\prime}\right)+\phi^{\prime} G\left(s_{t} ; \gamma, c\right)\left(a_{t}^{\prime}+b_{t}^{\prime}\right) /\left(a_{t}^{\prime}+b_{t}^{\prime}-2 c_{t}^{\prime}\right), \\
G\left(s_{t} ; \gamma, c\right)=\left(1+\exp \left\{-\gamma\left(s_{t}-c\right)\right\}\right)^{-1}
\end{gathered}
$$

\begin{tabular}{l|rrrrrr}
\hline & $\hat{\phi}$ & $\hat{\phi}^{\prime}$ & $\hat{\gamma}$ & $\hat{c}$ & $R^{2} a d j$ & Rel. SC \\
\hline Parameters & 2.15 & 3.23 & 4.56 & 1.62 & 0.80 & 0.93 \\
Standard errors & 0.651 & 0.901 & 5.331 & 0.270 & & \\
\hline
\end{tabular}

Notes: A moving average of four years of past inflation rates is used as the transition variable $s_{t}$. Relative SC denotes the Schwarz criterion of the STM relative to its linear counterpart.

\footnotetext{
${ }^{8}$ If $\gamma$ becomes a large function this model is equivalent to a two-regime threshold model. In the case of $\gamma$ close to zero, the logistic function is a constant and the model is a linear regression model.
} 


\subsection{Alternative quantification methods}

The most simple method to summarise the information of qualitative survey data is to compute a balance statistic of the survey answers. In its basic form the balance statistic is the balance of positive and negative answers. In the case of the consumer survey on price developments this is the difference between the fraction of participants that expects positive price changes (given by $C_{t}+D_{t}$ ) and those that expect price decreases (given by $A_{t}$ ). To employ the full set of information of the survey it is natural to augment the balance statistic and take into account the different notions of price increases. If one assumes that 'sharp' price increases should have a higher weight relative to 'slight' rises, we can compute the balance statistic as

$$
b a l_{t}=\left(0.5 C_{t}+D_{t}\right)-1.5 A_{t} .
$$

Obviously, this relative weighting scheme is quite ad hoc and not always empirically justified. ${ }^{9}$

A more flexible approach has been proposed by Pesaran (1984). He invented the socalled regression approach which builds on the less flexible balance statistic. The idea of this procedure is to use the linear relationship of the actual observed time series and the respondents' perception on this series as a yard stick to calibrate the relationship of future outcomes. This approach does not need the justification in terms of subjective probability distributions of individual respondents. ${ }^{10}$ In case of our survey the regression approach is set up on

$$
\pi_{t}=\alpha C_{t}^{\prime}+\beta D_{t}^{\prime}-\gamma A_{t}^{\prime}+v_{t}
$$

and the corresponding inflation expectations are given by $E_{t} \pi_{t+4}=\alpha C_{t}+\beta D_{t}-\gamma A_{t}$. Note, that the balance statistic is a restricted version of the regression approach, where $\alpha=0.5 c, \beta=c$ and $\gamma=1.5 c$ ( $c$ is only a scaling factor).

The regression approach is flexible and easy to apply. ${ }^{11}$ However, the theoretical

\footnotetext{
${ }^{9}$ To rescale the balance statistic to expected inflation one can use a similar method as for the probability method by regressing the future inflation rate on $b a l_{t}$ (i.e. $E_{t} \pi_{t+4}=c b a l_{t}$ ).

${ }^{10}$ However, in some cases the regression approach and the probability methods are equal (in the case where a uniform distribution is used).

${ }^{11}$ Pesaran (1987) also presented an asymmetric variant. The approach can also be extended to exhibit
} 
justification for consumers who do not have private information and normally observe an aggregate measure of prices (e.g. the CPI) is less clear. Pesaran (1987) assumes for his method that individuals experience different price developments for their firms, which implies that $A_{t}^{\prime}, B_{t}^{\prime}$ and $C_{t}^{\prime}$ from eq. (7) are approximately the fractions that experience a fall, a slight rise and a strong rise in prices, respectively. As long as the method can also be derived from the probability approach it may serve to us as an additional benchmark. ${ }^{12}$

\section{Results}

\subsection{Comparison and evaluation of different quantification methods}

Table 2: Connection to realized inflation

\begin{tabular}{llllll}
\hline & $1973-1980$ & $1981-1990$ & $1991-2000$ & $2001-2013$ & $1981-2013$ \\
\hline FS1 & 2.82 & $1.62^{* *}$ & 0.91 & $1.60^{*}$ & $1.43^{* * *}$ \\
FS2 & 2.76 & 1.53 & 0.87 & 1.49 & 1.34 \\
BK & $2.86^{*}$ & 1.54 & 0.84 & $1.39^{* * *}$ & $1.30^{*}$ \\
BKROLL & - & 1.57 & 0.88 & $0.96^{* * *}$ & 1.17 \\
KALFIL & 2.39 & 1.70 & 0.74 & $1.00^{* * *}$ & 1.20 \\
STM & 2.65 & 1.64 & 0.94 & $0.90^{* * *}$ & 1.19 \\
PES & 3.08 & 1.79 & 0.94 & $1.05^{* * *}$ & 1.31 \\
PESROLL & - & 1.69 & 1.12 & $0.89^{* * *}$ & 1.26 \\
AR & - & $2.23^{* *}$ & 1.22 & $1.16^{*}$ & 1.59 \\
ARROLL & - & 1.72 & $1.23^{*}$ & $1.06^{*}$ & 1.35 \\
CONSENS & - & - & - & $0.96^{* * *}$ & - \\
\hline
\end{tabular}

Notes: The table shows RMSEs for different quantification methods and for different subsamples. FS1 and FS2 denote the two different variants of Fluri and Spörndli (1987), BK is the Berk (1999) method, while BKROLL employs a rolling estimation scheme for this method, KALFIL uses the filtered estimates of the response threshold, STM is the smooth transition model, PES the original Pesaran method, PESROLL the rolling variant of Pesaran's method. Additional benchmarks are the autoregressive model estimated on the total sample (AR) and the AR model based on rolling estimates (ARROLL). CONSENS stands for the Consensus Economics data. Additionally, we test for differences relative to the FS2-model using a t-test in the spirit of Diebold and Mariano (1995), where ${ }^{*},{ }^{* *}$ and ${ }^{* * *}$ indicating significance at the $10 \%, 5 \%$ and $1 \%$ level, respectively.

First, we investigate how closely connected quantified expectations are with realized inflation rates. Table 2 shows the RMSEs of different quantification methods. First, we observe that the original Fluri and Spörndli procedures FS1 and FS2 display relatively large RMSEs relative to the alternatives. This is primarily caused by a large positive bias

time variation in the coefficients, e.g. by employing similar methods as in section 3.3.

${ }^{12}$ To allow of some time variation a rolling-regression approach is also applied to the Pesaran method. 
Table 3: Biases

\begin{tabular}{|c|c|c|c|c|c|c|c|c|c|c|}
\hline & \multicolumn{2}{|c|}{$1972 q 4-1980 q 4$} & \multicolumn{2}{|c|}{ 1981q1-1990q4 } & \multicolumn{2}{|c|}{ 1991q1-2000q4 } & \multicolumn{2}{|c|}{$2001 q 1-2013 q 4$} & \multicolumn{2}{|c|}{ 1981q1-2013q4 } \\
\hline & $\mathrm{ME}$ & $\mathrm{p}$-value & $\mathrm{ME}$ & $\mathrm{p}$-value & $\mathrm{ME}$ & $\mathrm{p}$-value & $\mathrm{ME}$ & p-value & $\mathrm{ME}$ & $\mathrm{p}$-value \\
\hline FS1 & -2.10 & 0.000 & -0.34 & 0.449 & 0.36 & 0.075 & 1.16 & 0.000 & 0.44 & 0.046 \\
\hline FS2 & -2.11 & 0.000 & -0.22 & 0.595 & 0.40 & 0.042 & 1.04 & 0.000 & 0.44 & 0.029 \\
\hline BK & -2.22 & 0.000 & -0.35 & 0.401 & 0.31 & 0.125 & 0.93 & 0.000 & 0.33 & 0.104 \\
\hline BKROLL & - & - & -0.18 & 0.686 & 0.08 & 0.721 & 0.14 & 0.518 & 0.02 & 0.908 \\
\hline KALFIL & -1.61 & 0.001 & -0.67 & 0.128 & 0.08 & 0.674 & 0.15 & 0.510 & -0.13 & 0.500 \\
\hline STM & -2.00 & 0.000 & -0.17 & 0.706 & 0.23 & 0.350 & 0.12 & 0.534 & 0.06 & 0.747 \\
\hline PES & -2.69 & 0.000 & -1.23 & 0.000 & -0.49 & 0.010 & 0.01 & 0.960 & -0.54 & 0.003 \\
\hline PESROLL & - & - & -0.77 & 0.058 & -0.44 & 0.115 & 0.08 & 0.689 & -0.35 & 0.070 \\
\hline $\mathrm{AR}$ & - & - & -0.55 & 0.378 & 0.66 & 0.024 & 0.63 & 0.005 & 0.27 & 0.318 \\
\hline ARROLL & - & - & 0.13 & 0.784 & 0.50 & 0.098 & 0.39 & 0.119 & 0.34 & 0.117 \\
\hline CONSENS & - & - & - & - & - & - & 0.38 & 0.062 & - & . \\
\hline
\end{tabular}

Notes: The table shows average biases and p values based on a regression of the error using Newey-West standard errors.

(see table 3) since the mid nineties. The average bias of yoy inflation after 2001 amounts to more than one percentage points and turns out to be statistically significant. This is a result of the assumption of fixed $\lambda$. It is therefore not surprising that Berk's method BK that uses the relation between perceived and realized inflation rates displays the same pathology (since it also assumes a constant $\lambda$ ). It seems therefore essential to take into account the time variation.

Figure 3 shows the time-varying response threshold $\lambda$ for several quantification methods. We see that the threshold from a moderate to a high price development changed significantly. It decreased substantially for all three methods roughly around the year 2000. Therefore, those methods that allow for some time variation of the scaling parameter display smaller errors and less bias.

Overall, the smooth transition model is quite accurate (in particular in the latest subperiod). But also the results based on the simple rolling procedure are encouraging. However, the simple rolling procedure has the disadvantage that a training sample is needed to estimate $\lambda$, which leaves us with less observations in the beginning of the sample.

Generally, most results of the different quantification methods are highly correlated (see sec. A.1 and figure 4). By taking into account the time variation of $\lambda$ one obtains similar results compared to those of professional forecasts. The professionals' forecasts are taken from Consensus Economics, which provides data for Switzerland since 1998q2. The 
Figure 3: Time variation in the response threshold $\lambda$ (moderate to high inflation perceptions)

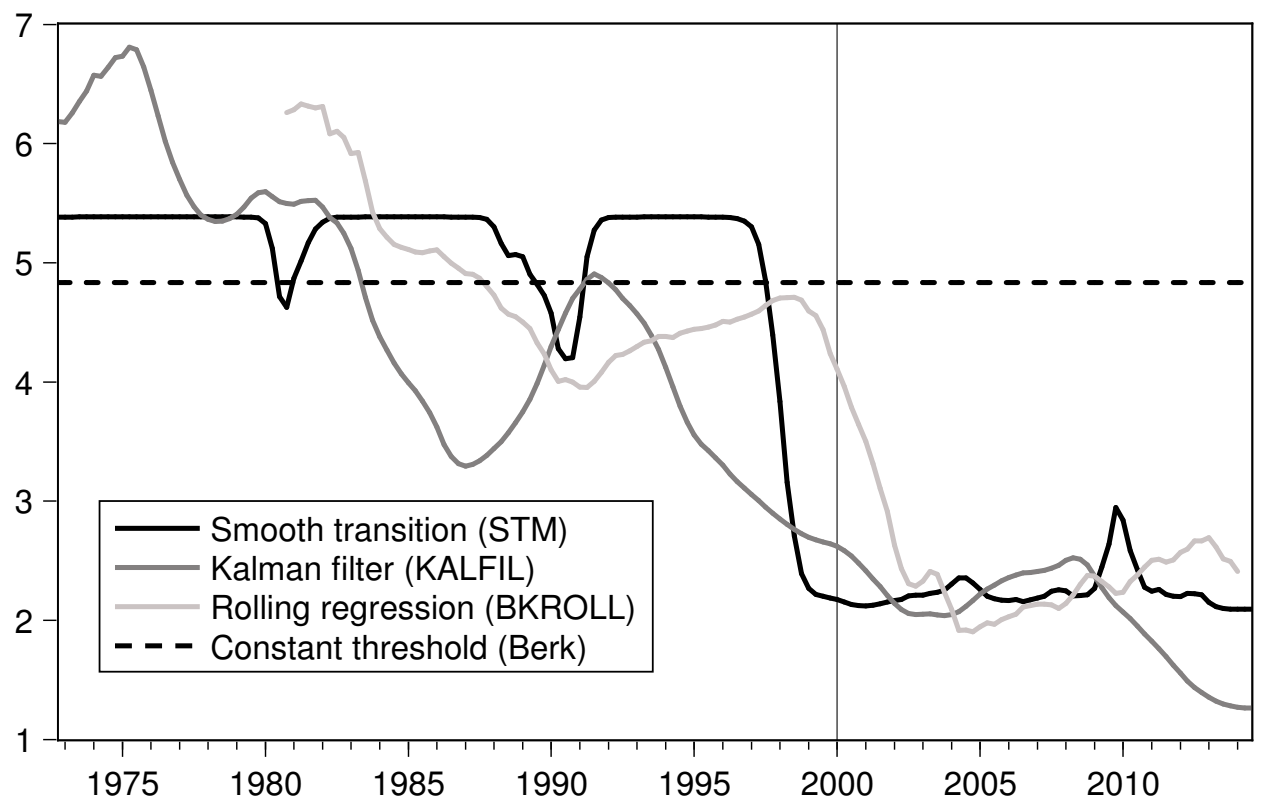

Figure 4: Expected and realized inflation

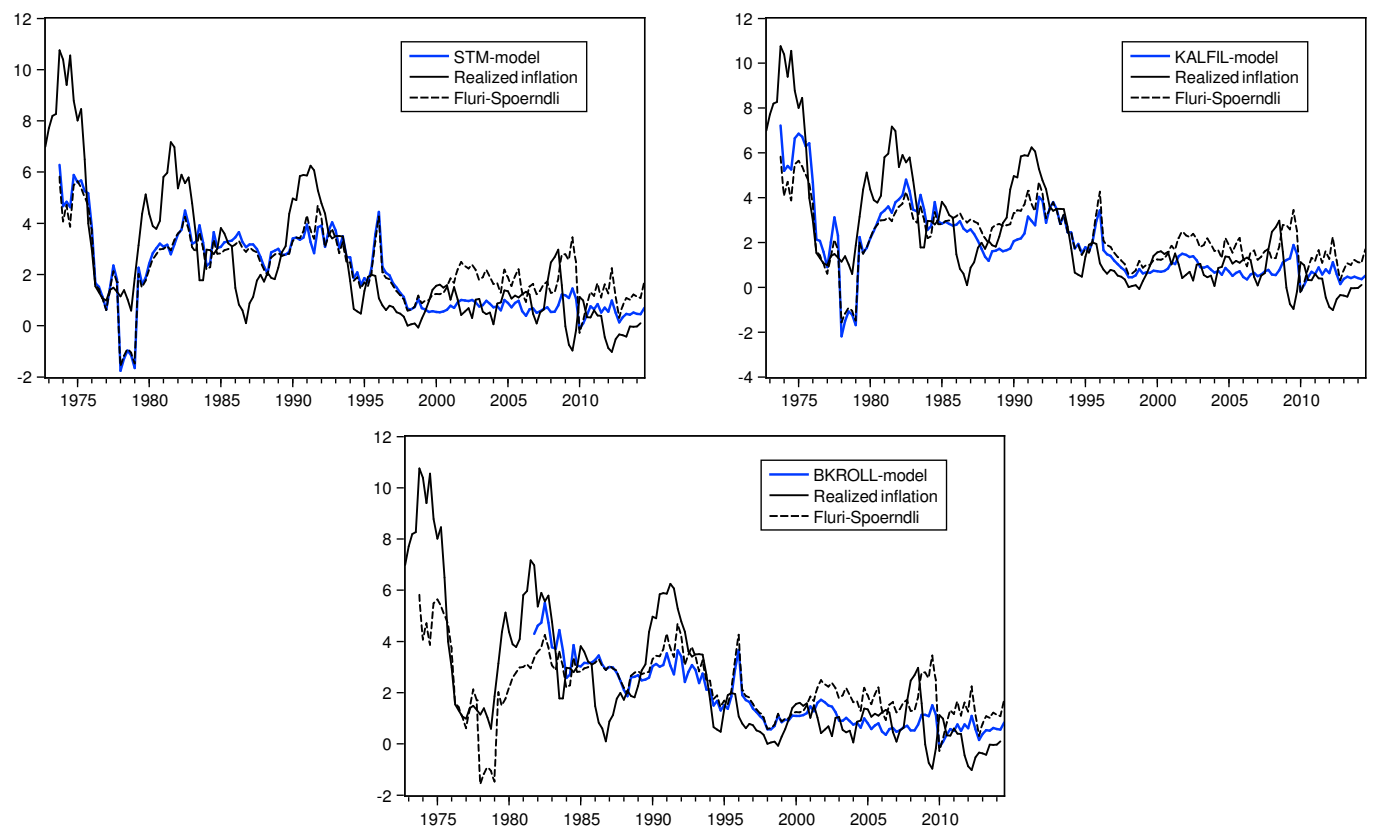

Notes: 3 different quantification methods are shown along with realized inflation and the original Fluri-Spörndli method. 
Figure 5: A comparison of calculated inflation expectations

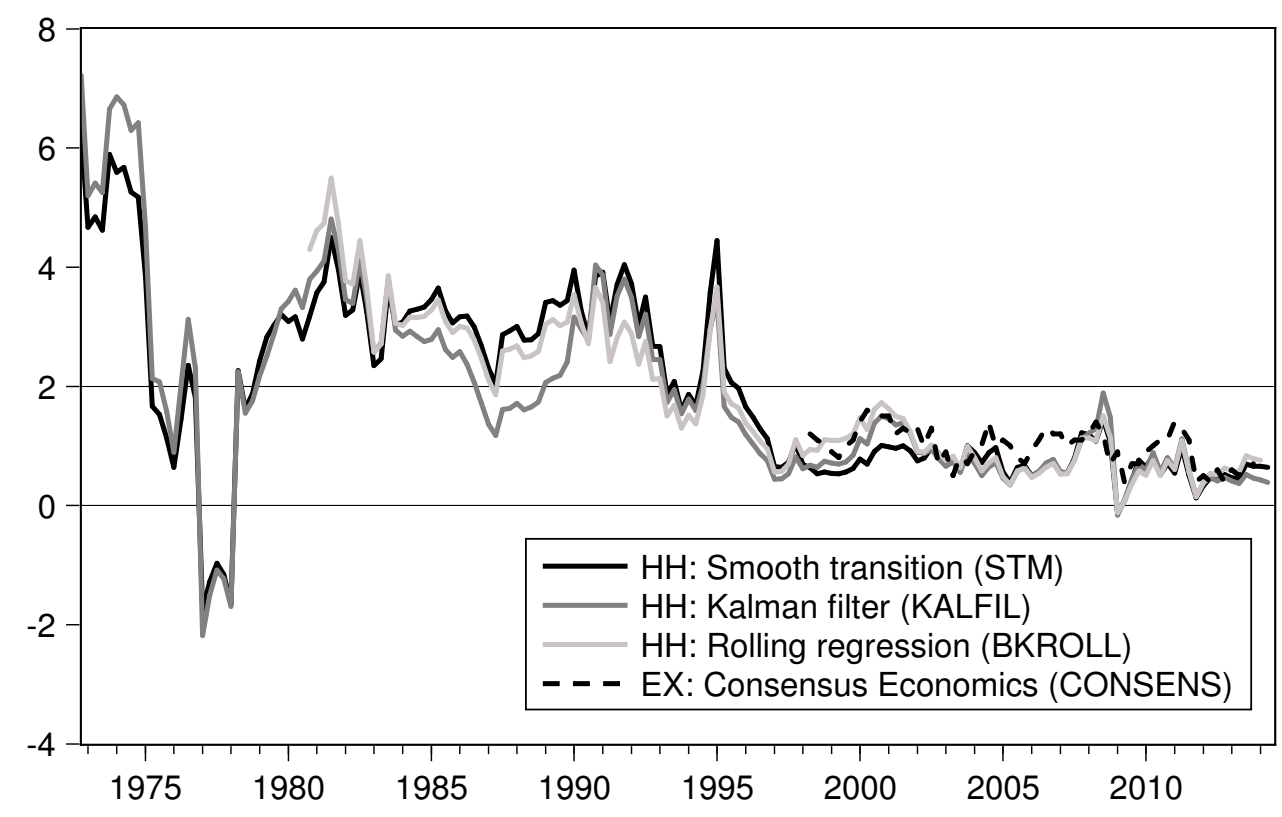

Notes: The figure shows 4 different inflation expectation measures over time for the one year ahead horizon.

quarterly series of Consensus Economics has the same forecast horizon and is collected slightly after the consumer survey.

It is also interesting to see how our inflation expectation measures perform relative to other benchmark models. Interestingly, survey expectations perform much better than autoregressive models. This may be mostly explained by the fact of instability (namely a shifting mean in inflation). But even when some time variation is introduced by rolling regressions, most expectation series show better accordance with realized inflation than AR models do. These findings are in line with Ang et al. (2007) who show that in the US survey based forecasts of inflation outperform econometric time-series models.

Generally, from the above empirical analysis we can infer that the Fluri and Spörndli procedure is unable to track inflation after 2000. Once allowing for time variation in $\lambda$, which can be inferred from the relationship of inflation with inflation perceptions we receive much more plausible results. The smooth-transition, the Kalman filter and the rolling regression approach show similar results (in particular since the late 90s) and 
are closely related to realized inflation. They also show similar properties than those of professional forecasts (see also figure 4 and 5). Households' and professional forecasters' expectations seem to be quite in line.

\subsection{Expectation formation}

Table 4 shows different tests on the formation of the quantified inflation expectations, similar to Mankiw et al. (2004). As the the smooth-transition model (STM), the Kalman filter approach (KALFIL) and the rolling regression method (BKROLL) gave encouraging results we focus in the following analysis on those models. Furthermore, we also perform the tests for the Consensus Economics data (CONSENS).

Panel A asks if the information is fully exploited. Can the forecast errors be predicted by any information in the inflation forecasts themselves? The joint tests of $a=b=0$ indicate that after 2000 information seems to be less exploited, e.g. the test for rationality can be rejected at the $5 \%$ level for the Kalman filter and at the $10 \%$ level for the rolling regression approach. Before 2000, there is less evidence of inefficiency of inflation expectations from surveys. Mankiw et al. (2004) finds mixed evidence of information being fully exploited for the US.

Panel B shows whether forecast errors are persistent. Do last year's forecast errors contain information for this year's forecast errors - if yes, that would violate the notion of full rationality. For the total sample, we find indeed that forecast errors seem to be persistent, which is in line with evidence for the US found by Mankiw et al. (2004).

Panel $\mathrm{C}$ asks whether publicly available information in the form of macroeconomic data can be useful in explaining forecast errors. This would imply that consumers could produce better inflation forecasts by taking into account macroeconomic data. For the full sample the macroeconomic data are jointly significant, for all methods the interest rate seems to have some explanatory power. Like Mankiw et al. we also find a negative coefficient for the interest rates. The negative coefficient can be interpreted in the following way, high interest rates lead to negative forecast errors, meaning that households predict an inflation rate that is too high in comparison to realized inflation. Interest rate hikes can imply tighter monetary policy and lower inflation in the future. Households underreact to tightening of interest rates in the sense that they predict an inflation rate in the future that 
lies above the realized one. After 2000 however, macroeconomic data has no explanatory power for the forecast errors, meaning, forecasts can still be inaccurate what is suggested in Panel A after 2000, but macroeconomic data does not seem to have prediction power for the forecast errors. Another explanation could be that inflation after 2000 was harder to predict by macroeconomic factors and therefore these indicators have no prediction power at all.

Panel D investigates a hypothesis raised by Lovell (1986), namely that forecasts often underestimate changes of the variable of interest. This seems to be the case for inflation expectations in general (both for consumers as well as for professionals).

Panel E shows whether expectations are forward-looking or adaptive. Over the full sample, expectations seem to have some limited forward-looking character. However, after 2000, the degree of forward-lookingness has declined. Lyziak (2010) for example finds in his study on inflation expectations in different European countries that forward-lookingness can vary over time.

Generally, our tests indicate that inflation expectations are not fully rational. But we cannot characterize them as purely adaptive. This is in line with the findings of Mankiw et al. (2004) for the US. Notably, we find that some characteristics of expectation formation has changed after 2000. One possible reason for this change might be the adjustment to a new policy framework by the SNB at that time.

\subsection{Some policy insights}

In this section we investigate whether expectations are anchored at a certain policy target and how disagreement evolves over time. The Swiss National Bank adjusted its monetary policy framework in the first quarter of 2000 (while the adjustment was announced in December 1999). Among other things it gave a clearer definition of what it considers as price stability. In its press release of 10 December 1999 it announced that it considers price stability to have been achieved with an inflation rate, as measured by the Swiss consumer price index, of less than $2 \%$ per annum. We therefore look at the period before and after the adjustment of the policy framework and whether it had any implications for the formation of expectations.

We conduct a simple test to see how closely inflation expectations follow the inflation 


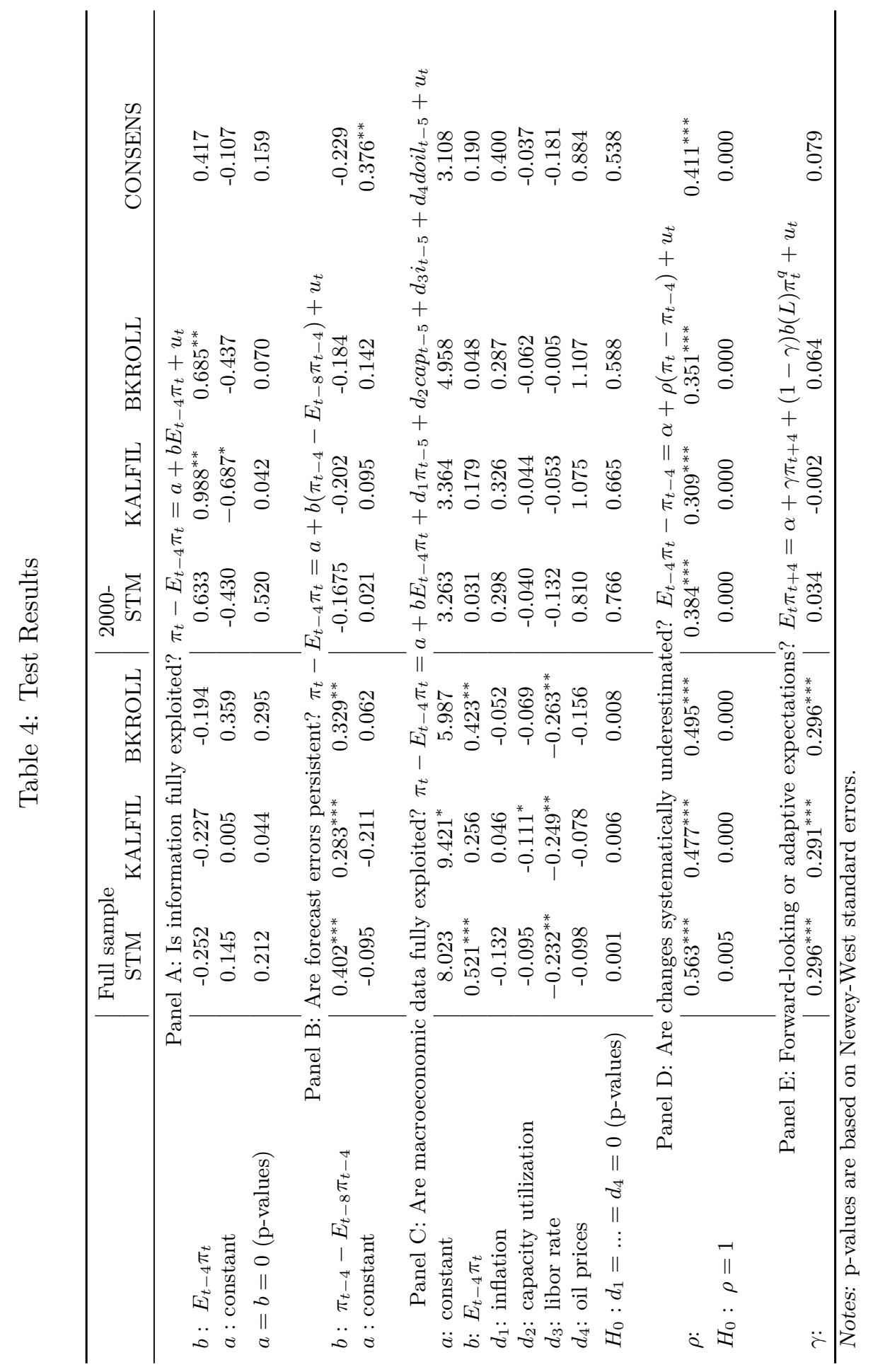


target (we follow the ideas of Bomfim and Rudebusch, 2000). This approach is related to the notion of regressive expectations where expectations adjust (or regress) to some long-run normal level (see Figlewski and Wachtel, 1981). In our case this could be the implicit inflation target of the central bank (or simply the long-term mean in inflation). Although the SNB defines price stability as an annual rise of less than $2 \%$ in the consumer price index, one can assume implicitly an inflation target of $1 \%$ over a longer run. This implicit 1\% target has quite a long tradition within the SNB (see Rich, 2003; Peytrignet, 2007). Before 2000, it is hard to assume any implicit inflation target, even though also at that time the $1 \%$ seems to have had a prominent place (see Rich, 2003). However, the realized inflation rate fluctuated much more and we therefore construct a proxy based on the recursive HP-filter with a high parameter for lambda (to receive a very persistent series). If we apply the recursive HP-filter from 2000 on, we get closely to the $1 \%$ value.

Table 5: Are inflation expectations anchored at the target?

\begin{tabular}{l|cccc}
\multicolumn{5}{c}{$E_{t} \pi_{t+4}=\lambda \pi_{t}^{t a r}+(1-\lambda) \pi_{t-1}+v_{t}$} \\
\hline & $\begin{array}{c}\lambda_{1}(\text { before 2000) } \\
\text { rec. HP (10000) }\end{array}$ & $\begin{array}{c}\lambda_{2}(2000-) \\
\text { rec. HP }(10000)\end{array}$ & $\begin{array}{c}\lambda_{2}^{\prime}(2000-) \\
1 \%\end{array}$ & $\begin{array}{c}H_{0}: \lambda_{1}>\lambda_{2} \\
\text { p-values }\end{array}$ \\
\hline STM & 0.23 & 0.79 & 0.76 & 0.018 \\
KALFIL & 0.18 & 0.67 & 0.66 & 0.011 \\
BKROLL & 0.57 & 0.64 & 0.72 & 0.180 \\
CONSENS & - & 0.70 & 0.80 & - \\
\hline
\end{tabular}

Notes: The tests show the relative importance of the inflation target to past inflation. A Wald test indicates whether this relationship has changed after 2000.

Table 5 shows the results. The tests indicate that the connection with the target has increased after 1999. It seems that inflation expectations became better anchored at the one-year horizon. This is clear evidence that the expectations display a substantial element of regressiveness since 2000. On the other hand this implies that the adaptive component seems to be less important. This indicates that there might be a link between higher inflation rates and a stronger adaptive component as suggested by Gibson (1972).

The fact that inflation expectations became more anchored could have several reasons: a) It is a direct result of the new monetary policy framework with an explicit definition of price stability, which helps to anchor inflation expectations of consumers at the communicated target. b) Due to lower persistence of actual inflation, inflation in general may have 
become harder to predict. People might therefore not adjust their expectations frequently, i.e. they stick to a certain trend in inflation. Nevertheless, table 5 might indicate at least some evidence that monetary policy became more credible after the introduction of the new concept.

\subsection{The evolution of forecast disagreement over time}

Figure 6 shows the evolution of disagreement/dispersion over time. The dispersion measure is given by $\hat{\sigma}_{t}=-2 \hat{\lambda}_{t} /\left(a_{t}+b_{t}-2 c_{t}\right)$. Dispersion dropped substantially around 2000, which is mainly a result of the lower estimated response threshold $\lambda$ which significantly decreased around 2000 (figure 3). This indicates that the change in the monetary policy framework not only anchored the expectations more closely at the target (see above), but also led to less dispersion in expectations.

Figure 6: Disagreement in inflation expectation measures

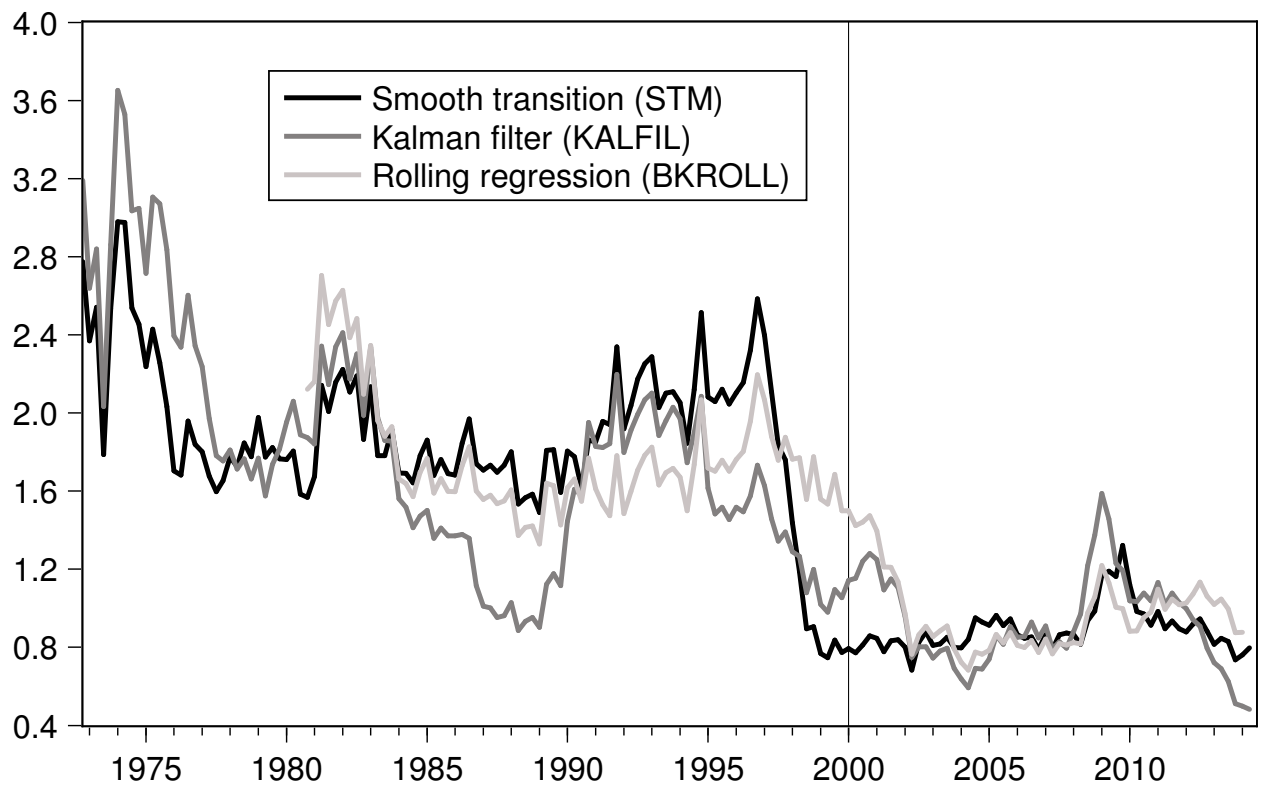

To investigate the evolution of disagreement in inflation expectations further, we can perform some formal tests (similar tests were conducted by Dovern et al., 2012; Andrade and Le Bihan, 2013). Table 6 shows two panels of test regressions for our three measures of inflation expectations. The first panel shows that disagreement is significantly lower after 
1999 and gives some evidence of possible correlation to recession periods in Switzerland. ${ }^{13}$ However, the effect that in periods of recessions (which might be associated with higher economic uncertainty) the measured dispersion of inflation expectations is larger can only be found for two measures (KALFIL and $B K R O L L)$.

In the second panel we investigate what other macroeconomic factors can explain the evolution of our dispersion measures. As proposed by Andrade and Le Bihan (2013) we use three measures to approximate macroeconomic uncertainty: a) the square of past inflation changes in the current period $\left.\left(\Delta \pi_{t-1}\right)^{2}, \mathrm{~b}\right)$ the square of changes in the expected inflation rate $\left(\Delta \pi_{t-1}\right)^{2}$ and c) the realized squared forecast error of inflation $e_{t}^{2}=\left(\pi_{t}-E_{t-4} \pi_{t}\right)^{2}$. Furthermore, we check for the relation with the inflation level as suggested by Mankiw et al. (2004) and economic activity measured by the output gap ogap. ${ }^{14}$

Table 6: Disagreement and the business cycle

\begin{tabular}{|c|c|c|c|}
\hline & STM & KALFIL & BKROLL \\
\hline \multicolumn{4}{|c|}{$\sigma_{i, t}=\beta_{0}+\beta_{1}$ rec $_{t}+\beta_{2}$ post-1999+ut } \\
\hline$\beta_{0}$ & $1.87^{* * *}$ & $1.78^{* * *}$ & $1.74^{* * *}$ \\
\hline$\beta_{1}$ & 0.09 & $0.18^{*}$ & $0.16^{* * *}$ \\
\hline$\beta_{2}$ & $-0.99^{* * *}$ & $-0.87^{* * *}$ & $-0.79^{* * *}$ \\
\hline$R^{2} a d j$. & 0.69 & 0.41 & 0.71 \\
\hline \multicolumn{4}{|c|}{$\sigma_{i, t}=\beta_{3}+\beta_{4} \pi_{t-1}+\beta_{5} \operatorname{ogap}_{t}+\beta_{6}\left(\Delta \pi_{t-1}\right)^{2}+\beta_{7}\left(\Delta E_{t} \pi_{t+4}\right)^{2}+\beta_{8} e_{t}^{2}+\beta_{9}$ post-1999 $+v_{t}$} \\
\hline$\beta_{3}$ & $1.59^{* * *}$ & $1.15^{* * *}$ & $1.60^{* * *}$ \\
\hline$\beta_{4}$ & $0.06^{* * *}$ & $0.15^{* * *}$ & $0.05^{* * *}$ \\
\hline$\beta_{5}$ & $-0.06^{* * *}$ & $-0.10^{* * *}$ & $-0.03^{* *}$ \\
\hline$\beta_{6}$ & -0.01 & $0.07^{* * *}$ & 0.05 \\
\hline$\beta_{7}$ & 0.01 & $0.04^{* * *}$ & $0.11^{* *}$ \\
\hline$\beta_{8}$ & $0.02^{* *}$ & 0.01 & -0.01 \\
\hline$\beta_{9}$ & $-0.76^{* * *}$ & $-0.36^{* * *}$ & $-0.67^{* * *}$ \\
\hline$R^{2} a d j$. & 0.77 & 0.78 & 0.77 \\
\hline Sample & $1972 q 4-2013 q 4$ & $1972 q 4-2013 q 4$ & $1984 q 4-2013 q 4$ \\
\hline
\end{tabular}

Notes: Newey-West standard errors. The dependent variable is the dispersion measure of expected inflation rates. "post-1999" denotes a dummy variable that equals 0 before 2000 and 1 thereafter; "rec" denotes a dummy variable that equals 1 during recession and 0 otherwise; "ogap" denotes the ex post output gap estimated of the SNB production function approach. Statistical significance at $*: 10 \%, * *: 5 \%$, and $* * *: 1 \%$.

We find that the dispersion measures are related to macroeconomic uncertainty variables. Higher macroeconomic volatility with respect to inflation seems to be correlated with dispersion. ${ }^{15}$ Furthermore, we can confirm Mankiw et al. (2004)'s finding that dis-

\footnotetext{
${ }^{13}$ We employ the recession definitions from Siliverstovs (2013).

${ }^{14}$ We take the output gap definition by the SNB which is based on a production function approach.

${ }^{15}$ Other measures such as the relative price variability were not found to be a significant determinant of
} 
persion rises with the level of inflation. Additionally, we find that in downturns (or in periods of negative output gaps) disagreement is on average larger. Interestingly, the time dummy remains significant after 1999 although we controlled for other major factors that influence dispersion. This might be further evidence that monetary policy might have contributed to the decline in disagreement.

Taking together the findings from the last two subsections there is evidence that the expectation formation process of Swiss consumers changed as a result of the new monetary policy framework of the SNB. This is fully in line with the famous Lucas critique (Lucas, 1976).

\subsection{How do households and professional forecasters relate to each other?}

To explain the dynamics of inflation expectations of households, Carroll (2003) proposed a model of sticky information. The basic idea is that household update their information set infrequently and when they update they take into account the information of professionals which are generally more informed and closer to market relevant information.

Table 7: Granger causality tests for household and expert expectations

\begin{tabular}{l|rrr}
\hline \multicolumn{3}{c}{$E_{t}^{i} \pi_{t+4}=a+\sum_{j=1}^{p} b_{j} E_{t-j}^{H H} \pi_{t+4-j}+\sum_{j=1}^{p} c_{j} E_{t-j}^{E X} \pi_{t+4-j}$} \\
& STM & KALFIL & BKROLL \\
\hline$E_{t}^{H H} \pi_{t+4} \nrightarrow E_{t}^{E X} \pi_{t+4}$ & 0.7115 & 0.5911 & 0.3265 \\
$E_{t}^{E X} \pi_{t+4} \nrightarrow E_{t}^{H H} \pi_{t+4}$ & 0.0004 & 0.0001 & 0.0014 \\
\hline
\end{tabular}

Notes: The table displays $p$ values for the null hypothesis of variable $i$ is not Granger causing variable $j$.

One statistical pre-condition for this view is that inflation expectations of professionals Granger-cause household's expectations and not vice versa. Table 7 shows the results of this tests for the sample period where both measures exist. As stated by Carroll's (2003) model this is indeed the case.

As a next step, the expectation formation of the households can now be explained by professional expectations (see Carroll, 2003; Doepke et al., 2008). The sticky information model claims that information disseminates by a certain speed from professionals to dispersion. 
households, i.e. a fraction of the households updates its information set and absorbs news from professional forecasts.

Table 8: Sticky expectations in Switzerland

\begin{tabular}{|c|c|c|c|c|c|c|}
\hline & \multirow[b]{2}{*}{$\lambda_{0}$} & \multirow[b]{2}{*}{$\lambda_{1}$} & \multirow[b]{2}{*}{$\lambda_{2}$} & \multicolumn{3}{|c|}{ p-values } \\
\hline & & & & $\lambda_{1}+\lambda_{2}=1$ & $\lambda_{1}=0.25$ & $\operatorname{LM}(4)$ \\
\hline \multicolumn{7}{|c|}{ a. unrestricted: $E_{t}^{H}{ }^{H} \pi_{t+4}=\lambda_{0}+\lambda_{1} E_{t}^{E X} \pi_{t+4}+\lambda_{2} E_{t-1}^{H H} \pi_{t+3}$} \\
\hline STM & 0.152 & $0.246^{* *}$ & $0.439^{* * *}$ & 0.006 & 0.972 & 0.665 \\
\hline KALFIL & -0.011 & $0.405^{* * *}$ & $0.486^{* * *}$ & 0.335 & 0.222 & 0.517 \\
\hline BKROLL & 0.033 & $0.271^{* *}$ & $0.634^{* * *}$ & 0.370 & 0.865 & 0.553 \\
\hline \multicolumn{7}{|c|}{ b. restricted: $E_{t}^{H H} \pi_{t+4}=\lambda_{1} E_{t}^{E X} \pi_{t+4}+\left(1-\lambda_{1}\right) E_{t-1}^{H H} \pi_{t+3}$} \\
\hline STM & & $0.195^{* *}$ & & & 0.462 & 0.373 \\
\hline KALFIL & & $0.320^{* * *}$ & & & 0.420 & 0.530 \\
\hline BKROLL & & $0.273^{* * *}$ & & & 0.793 & 0.512 \\
\hline
\end{tabular}

Notes: This table shows two versions of the sticky information model. a. is the version with the unrestricted model and $\mathrm{b}$. is the version that implies $\lambda_{1}+\lambda_{2}=1$. The LM-test tests for remaining autocorrelation up to the fourth lag.

Table 8 shows, that in Switzerland, similar to the United States, in each quarter only a fourth of the households absorbs latest forecasts of professionals, i.e. $\hat{\lambda} \approx 0.25$. Or put differently, the sticky information model implies that on average households update their information set only once a year. Interestingly, this value is in contrast to the larger European countries where average frequency of information updating is estimated to be 18 months (see Doepke et al., 2008). This indicates that Swiss households seem to process information faster than in most European countries (but similar to US consumers).

\section{Conclusion}

We showed that quantification methods allowing for time variation in the response threshold and including survey responses on perceived past price developments delivered the most promising results in tracking realized inflation. As the inflation environment changed in the nineties to significantly lower inflation and inflation volatility, models that do not allow for time variation in the response threshold like Fluri and Spörndli (1987) become heavily biased after 2000. In particular, the smooth transition model that we suggest as an innovation to quantifying qualitative survey response data on inflation expectations performs well. 
Tests on expectation formation showed that since 2000 expectation formation has changed in many ways. Inflation seems to be harder to forecast, while macroeconomic data cannot explain the forecast errors after 2000. Households have become less forwardlooking, however, expectations are better anchored. Disagreement/ dispersion has declined significantly as well, possibly on the back of an adjustment of the SNB's monetary policy framework in 2000 where a clear definition of price stability was introduced. Interestingly, information dissemination works similar as in the US, from professionals to households and the average household updates the information set roughly once a year. 


\section{References}

Andrade, P. AND H. Le Bihan (2013): "Inattentive Professional Forecasters," Journal of Monetary Economics, 60, 967-982.

Ang, A., G. Bekaert, And M. Wei (2007): "Do macro variables, asset markets, or surveys forecast inflation better?" Journal of Monetary Economics, 54, 1163-1212.

Batchelor, R. A. (1982): "Expectations, Output and Inflation: The European Experience," European Economic Review, 17, 1-25.

Batchelor, R. A. AND A. B. OrR (1988): "Inflation Expectations Revisited," Economica, 55, 317-331.

Berk, J. M. (1999): "Measuring Inflation Expectations: A Survey Data Approach," Applied Economics, 31, 1467-1480.

Bomfim, A. N. And G. D. Rudebusch (2000): "Opportunistic and Deliberate Disinflation under Imperfect Credibility," Journal of Money, Credit and Banking, 32, 707-21.

Breitung, J. And M. Schmeling (2013): "Quantifying Survey Expectations: What's Wrong with the Probability Approach?" International Journal of Forecasting, 29, 142154.

Carlson, J. A. And M. Parkin (1975): "Inflation Expectations," Economica, 42, 123138.

Carroll, C. D. (2003): "Macroeconomic Expectations Of Households And Professional Forecasters," The Quarterly Journal of Economics, 118, 269-298.

Dasgupta, S. And K. Lahiri (1992): "A Comparative Study of Alternative Methods of Quantifying Qualitative Survey Responses Using NAPM Data," Journal of Business 85 Economic Statistics, 10, 391-400.

Diebold, F. X. And R. S. Mariano (1995): "Comparing Predictive Accuracy," Journal of Business \&3 Economic Statistics, 13, 253-63.

Doepke, J., J. Dovern, U. Fritsche, and J. Slacalek (2008): "The Dynamics of European Inflation Expectations," The B.E. Journal of Macroeconomics, 8, 12.

Dovern, J., U. Fritsche, And J. Slacalek (2012): "Disagreement Among Forecasters in G7 Countries," The Review of Economics and Statistics, 94, 1081-1096.

Figlewski, S. AND P. WAChtel (1981): "The Formation of Inflationary Expectations," The Review of Economics and Statistics, 63, 1-10.

Fluri, R. AND E. SpÖrndli (1987): "Rationality of Consumers? Price Expectations - Empirical Tests Using Swiss Qualitative Survey Data," in Contributions of Business Cycle Surveys to Empirical Economics, ed. by K.-H. Oppenländer and G. Poser, Papers presented at the 18th CIRET Conference, 156-177.

Gibson, W. E. (1972): "Interest Rates and Inflationary Expectations: New Evidence," American Economic Review, 62, 854-865.

LAhiRI, K. And Y. Zhao (2014): "Quantifying Survey Expectations: A Critical Review and Generalization of the Carlson-Parkin Method," Tech. rep., University at Albany. 
Lovell, M. C. (1986): "Tests of the Rational Expectations Hypothesis," American Economic Review, 76, 110-24.

Lucas, R. E. (1976): "Econometric Policy Evaluation: A Critique," in The Phillips Curve and Labor Markets, ed. by K. Brunner and A. Meltzer, Amsterdam: North-Holland Publishing Company, vol. 1 of Carnegie-Rochester Conferences on Public Policy, 19-46.

LYZIAK, T. (2010): "Measuring consumer inflation expectations in Europe and examining their forward-lookingness," in The IFC's contribution to the 57th ISI Session, Durban, August 2009, ed. by B. for International Settlements, Bank for International Settlements, vol. 33 of IFC Bulletins chapters, 155-201.

Mankiw, N. G., R. Reis, And J. Wolfers (2004): "Disagreement about Inflation Expectations," in NBER Macroeconomics Annual 2003, ed. by M. Gertler and K. Rogoff, The MIT Press, vol. 18.

NARdo, M. (2003): "The Quantification of Qualitative Survey Data," Journal of Economic Surveys, 17, 645-668.

Nielsen, H. (2003): "Inflation Expectations in the EU - Results from Survey Data," Working paper, FU and HU Berlin.

Pesaran, M. H. (1984): "Expectations Formation and Macroeconomic Modelling," in Contemporary Macroeconomic Modelling, ed. by P. Magrange and P-Muet, Oxford: Blackwell, 27-53. (1987): The Limits to Rational Expectations, Oxford: Blackwell.

Peytrignet, M. (2007): "The Money Supply as an Intermediate Monetary Target," in The Swiss National Bank 1907 - 2007, Swiss National Bank, 236-254.

RIch, G. (2003): "Swiss Monetary Targeting 1974 - 1996: The Role of Internal Policy Analysis," Working Paper 236, European Central Bank.

Scheufele, R. (2011): “Are Qualitative Inflation Expectations Useful to Predict Inflation?" OECD Journal: Journal of Business Cycle Measurement and Analysis, 2011, $29-53$.

SEITz, H. (1988): "The Estimation of Inflation Forecasts from Business Survey Data," Applied Economics, 20, 427-438.

Siliverstovs, B. (2013): "Dating Business Cycles in Historical Perspective: Evidence for Switzerland," Journal of Economics and Statistics (Jahrbuecher fuer Nationaloekonomie und Statistik), 233, 661-679.

Smith, J. AND M. MCAller (1995): "Alternative Procedures for Converting Qualitative Response Data to Qualitative Expectations: An Application to Australian Manufacturing," Journal of Applied Econometrics, 10, 165-185.

Stulz, J. (2007): "Exchange Rate Pass-Through in Switzerland: Evidence from Vector Autoregressions," Swiss National Bank Economic Studies.

Theil, H. (1952): "On the Shape of Economic Microvariables and the Munich Business Test," Revue del'Institut International de Statistique, 20, 105-120. 
van Dijk, D., T. Teräsvirta, And P. H. Frances (2002): "Smooth Transition Autoregressive Models - A Survey of Recent Developments," Econometric Reviews, 21, $1-47$. 


\section{A Appendix}

\section{A.1 Descriptive statistics}

Table 9: Pairwise correlations

\begin{tabular}{|c|c|c|c|c|c|c|c|c|c|c|c|}
\hline $1981 q 1-2013 q$ & 4 FS1 & FS2 & BK & BKROLL & KALFIL & STM & PES & PESROLL & AR & ARROLL & CONSENS \\
\hline FS1 & 1 & & & & & & & & & & \\
\hline FS2 & 0.98 & 1 & & & & & & & & & \\
\hline BK & 0.97 & 1.00 & 1 & & & & & & & & \\
\hline BKROLL & 0.83 & 0.89 & 0.90 & 1 & & & & & & & \\
\hline KALFIL & 0.84 & 0.89 & 0.90 & 0.96 & 1 & & & & & & \\
\hline STM & 0.83 & 0.90 & 0.91 & 0.96 & 0.94 & 1 & & & & & \\
\hline PES & 0.94 & 0.97 & 0.97 & 0.87 & 0.90 & 0.88 & 1 & & & & \\
\hline PESROLL & 0.83 & 0.88 & 0.89 & 0.94 & 0.92 & 0.90 & 0.90 & 1 & & & \\
\hline $\mathrm{AR}$ & 0.46 & 0.54 & 0.55 & 0.66 & 0.77 & 0.69 & 0.54 & 0.61 & 1 & & \\
\hline ARROLL & 0.58 & 0.66 & 0.67 & 0.84 & 0.85 & 0.84 & 0.66 & 0.76 & 0.78 & 1 & \\
\hline Mean & 2.20 & 2.21 & 2.10 & 1.79 & 1.62 & 1.82 & 1.23 & 1.41 & 1.99 & 2.11 & \\
\hline $\mathrm{SD}$ & 0.97 & 1.01 & 0.98 & 1.21 & 1.14 & 1.27 & 1.12 & 1.12 & 1.34 & 1.40 & \\
\hline \multirow[t]{2}{*}{$2001 \mathrm{q} 1-2013 \mathrm{q} 4$} & & & & & & & & & & & \\
\hline & FS1 & FS2 & BK & BKROLL & KALFIL & STM & PES & PESROLL & $\mathrm{AR}$ & ARROLL & CONSENS \\
\hline FS1 & 1 & & & & & & & & & & \\
\hline FS2 & 0.98 & 1 & & & & & & & & & \\
\hline BK & 0.97 & 1.00 & 1 & & & & & & & & \\
\hline BKROLL & 0.86 & 0.92 & 0.93 & 1 & & & & & & & \\
\hline KALFIL & 0.91 & 0.93 & 0.93 & 0.96 & 1 & & & & & & \\
\hline STM & 0.95 & 0.98 & 0.99 & 0.89 & 0.91 & 1 & & & & & \\
\hline PES & 0.97 & 0.99 & 0.99 & 0.92 & 0.94 & 0.98 & 1 & & & & \\
\hline PESROLL & 0.72 & 0.72 & 0.72 & 0.66 & 0.68 & 0.66 & 0.73 & 1 & & & \\
\hline $\mathrm{AR}$ & -0.06 & -0.04 & -0.03 & 0.03 & 0.05 & -0.02 & -0.02 & 0.23 & 1 & & \\
\hline ARROLL & -0.57 & -0.54 & -0.53 & -0.40 & -0.43 & -0.47 & -0.52 & -0.59 & 0.48 & 1 & \\
\hline CONSENS & 0.55 & 0.54 & 0.52 & 0.52 & 0.54 & 0.51 & 0.50 & 0.57 & 0.07 & -0.37 & 1 \\
\hline Mean & 1.73 & 1.62 & 1.51 & 0.74 & 0.73 & 0.72 & 0.59 & 0.65 & 1.14 & 1.00 & 0.95 \\
\hline $\mathrm{SD}$ & 0.76 & 0.69 & 0.65 & 0.36 & 0.38 & 0.30 & 0.63 & 0.41 & 0.61 & 0.44 & 0.31 \\
\hline
\end{tabular}

Notes: Table shows pairwise correlations as well as the mean and standard deviations for the different measures for two samples. 


\section{Recent SNB Working Papers}

2014-11 Rina Rosenblatt-Wisch and Rolf Scheufele: Quantification and characteristics of household inflation expectations in Switzerland.

2014-10 Gregor Bäurle and Daniel Kaufmann: Exchange rate and price dynamics in a small open economy - the role of the zero lower bound and monetary policy regimes.

2014-9 Matthias Gubler and Christoph Sax: Skill-Biased Technological Change and the Real Exchange Rate.

2014-8 Tommaso Mancini Griffoli, Christoph Meyer, Jean-Marc Natal and Attilio Zanetti: Determinants of the Swiss Franc Real Exchange Rate.

2014-7 Konrad Adler and Christian Grisse: Real exchange rates and fundamentals: robustness across alternative model specifications.

2014-6 Matthias Gubler: Carry Trade Activities: A Multivariate Threshold Model Analysis.

2014-5 Raphael A. Auer and Aaron Mehrotra: Trade linkages and the globalisation of inflation in Asia and the Pacific.

2014-4 Cyril Monnet and Thomas Nellen: The Collateral Costs of Clearing.

2014-3 Filippo Brutti and Philip Sauré: Repatriation of Debt in the Euro Crisis: Evidence for the Secondary Market Theory.

2014-2 Simone Auer: Monetary Policy Shocks and Foreign Investment Income: Evidence from a large Bayesian VAR.
2014-1 Thomas Nitschka: The Good? The Bad? The Ugly? Which news drive (co)variation in Swiss and US bond and stock excess returns?

2013-11 Linda S. Goldberg and Christian Grisse: Time variation in asset price responses to macro announcements.

2013-10 Robert Oleschak and Thomas Nellen: Does SIC need a heart pacemaker?

2013-9 Gregor Bäurle and Elizabeth Steiner: How do individual sectors respond to macroeconomic shocks? A structural dynamic factor approach applied to Swiss data.

2013-8 Nikolay Markov and Thomas Nitschka: Estimating Taylor Rules for Switzerland: Evidence from 2000 to 2012.

2013-7 Victoria Galsband and Thomas Nitschka: Currency excess returns and global downside market risk.

2013-6 Elisabeth Beusch, Barbara Döbeli, Andreas Fischer and Pınar Yeşin: Merchanting and Current Account Balances.

2013-5 Matthias Gubler and Matthias S. Hertweck: Commodity Price Shocks and the Business Cycle: Structural Evidence for the U.S.

2013-4 Christian Grisse and Thomas Nitschka: On financial risk and the safe haven characteristics of Swiss franc exchange rates.

2013-3 Simone Meier: Financial Globalization and Monetary Transmission.
From 2014, this publication series will be renamed SNB Working Papers.

All SNB Working Papers are available for download at: www.snb.ch, Research

Subscriptions or individual issues can be ordered at: Swiss National Bank

Library

P.O. Box

$\mathrm{CH}-8022$ Zurich

Phone: +41446313284

Fax: +41446318114

E-mail: library@snb.ch 
